\title{
DIALOGANDO ENTRE PERCURSOS ABOLICIONISTAS E IDEAIS MINIMALISTAS: PARÂMETROS PARA A BUSCA DE SOLUÇÕES ALTERNATIVAS ÀS CONSEQUÊNCIAS DA CULTURA DO ENCARCERAMENTO
}

\author{
Giana Lisa Zanardo Sartori ${ }^{87}$ \\ Diana Casarin Zanatta ${ }^{88}$ \\ Andrey Henrique Andreolla ${ }^{89}$
}

Recebido em: 07/05/2018

Aprovado em: 08/06/2018

\begin{abstract}
RESUMO
O ponto de partida do presente artigo foi, em um primeiro momento, entender como a pena de prisão se apresenta nos dias atuais. Compreendendo as suas consequências e os processos aos quais submete a sua clientela, e percebendo-se, assim, que a principal instituição do sistema penal não atende aos anseios aos quais é chamada a responder, passou-se, então, à análise de soluções alternativas ao encarceramento - objeto principal de estudo deste trabalho. Partindo-se, neste ponto, da obra Em Busca das Penas Perdidas, de Eugenio Raul Zaffaroni, o trabalho trouxe propostas de solução para o problema que enfrenta - o cárcere e suas consequências - por meio de autores abolicionistas e minimalistas, os quais possuem, em comum, sugestões e projetos de supressão do sistema penal vigente - no todo ou em parte -, principalmente no que diz respeito à substituição da pena de prisão por outros mecanismos de solução de conflitos e/ou reparação de danos. Para tanto, no presente estudo, foi utilizado o método analítico-descritivo, por meio da pesquisa bibliográfica.
\end{abstract}

Palavras-chave: Abolicionismo. Minimalismo. Prisão. Soluções alternativas.

\section{INTRODUÇÃO}

\footnotetext{
${ }^{87}$ Doutora em Ciência Jurídica pela UNIVALI/SC. Professora do curso de Direito e do curso de Fisioterapia da URI-Erechim/RS. Advogada. Conciliadora/Mediadora Judicial.

${ }^{88}$ Mestre em Direito pela Universidade Regional Integrada (URI) Campus Santo Ângelo/RS. Delegada de Polícia Titular da $11^{\mathrm{a}}$ Delegacia de Polícia Regional de Erechim/RS. Professora do Curso de Direito na Universidade Regional Integrada - URI-Erechim/RS.

${ }^{89}$ Mestrando em Ciências Criminais pela Pontifícia Universidade Católica do Rio Grande do Sul. Advogado.
} 
A pena de prisão deveria refletir os objetivos aos quais ela é destinada: além da devida retribuição e da prevenção ao cometimento de crimes, a consequente ressocialização do apenado, para que, após o período no cárcere, retorne apto ao convívio social. Essa é a teoria; entretanto, não é o que acontece.

Ao contrário da retribuição, o que se vê na atualidade é uma legítima afronta aos direitos humanos - inclusive, preceituados na Constituição Federal Brasileira. Penas cruéis e desumanas que, muitas vezes, perpassam a figura do encarcerado ${ }^{90}$, transformam-se em realidade dia após dia nos presídios nacionais. Além do mais, o óbice ao cometimento de novos delitos não é alcançado, bastando para tanto, verificar os números do aprisionamento, que crescem anualmente ${ }^{91}$. Por fim, ela não ressocializa, conforme deixa claro o acentuado número de reincidências que ocorrem, hoje, no Brasil. ${ }^{92}$.

Tais problemas levam ao enfrentamento da seguinte questão: se a prisão não funciona, o que se colocar em seu lugar? Para responder a tal pergunta, a partir de Eugenio Raul Zaffaroni, na obra Em Busca das Penas Perdidas, encontram-se autores que partilham de ideais um tanto quanto radicais, porém, centrados no princípio basilar da dignidade humana. Referidos autores, contemplados nas figuras de Louk Hulsman, Thomas Mathiesen e Nils Christie, abordam pontos centrais sobre o assunto que aborda o presente trabalho. Em tons comuns de crítica ao sistema punitivo, escorrendo por notas minimalistas e abolicionistas, eles buscam apontar os problemas vivenciados na atualidade pela instituição cárcere e propor medidas alternativas que, em muito, evitem o caimento do considerado culpado por determinado fato no sistema prisional.

Importante ressaltar que, para melhor compreensão do trabalho, a questão abolicionista será apresentada como um percurso, e não uma teoria acabada, posto que visa, passo a passo, atingir grandes objetivos, por meio de enredos que andem no sentido da nãoutilização da pena de prisão. Assim, estuda-se, também, os ideais minimalistas, que em vários pontos conversam com as propostas abolicionistas radicais, muitas vezes entendendo-se como

\footnotetext{
${ }^{90} \mathrm{O}$ que não é o fato da mãe que foi presa, com um filho recém-nascido, senão a configuração dos efeitos da pena para além do apenado (neste caso, a criança)? Ver mais em: RIBEIRO, Juliana do Val; VIRGENS, Eufrásia Maria Souza das. A absurda prisão de mão com bebê recém-nascido. Estadão. Disponível em: http://politica.estadao.com.br/blogs/fausto-macedo/a-absurda-prisao-de-mae-com-bebe-recem-nascido/. Acesso em: 22 de fevereiro de 2018.

${ }^{91}$ Conforme Levantamento Nacional de Informações Penitenciárias, atualizado em Junho de 2016, que fez um levantamento desde 1990, que resulta em um gráfico no qual, até os dias atuais, ano a ano o número de pessoas encarceradas no Brasil só aumenta. Disponível em: http://www.justica.gov.br/news/ha-726-712-pessoas-presasno-brasil/relatorio_2016_junho.pdf. Acesso em 27 de maio de 2018.

${ }^{92}$ O Brasil possui uma taxa de reincidência de cerca de $70 \%$, conforme Relatório de Pesquisa em Reincidência Criminal no Brasil - $\quad$ IPEA. http://www.cnj.jus.br/files/conteudo/destaques/arquivo/2015/07/572bba385357003379ffeb4c9aa1f0d9.pdf. Acesso em: 27 de maio de 2018.
} 
instrumento para a redução do dano causado pelo sistema penal, e, em outras, como estratégia para atingir-se, ao fim, a sua total abolição.

Desta forma, a primeira parte do artigo se dá no sentido de apontar a ineficácia da pena de prisão, analisando-a em sua realidade. Conhecendo as (dis) funções do cárcere e entendendo o seu (não) funcionamento - no que diz respeito a atingir ou não os objetivos a que se propõe -, o segundo momento busca em autores consagrados, que lecionam nas linhas do abolicionismo e do minimalismo penal, a partir da classificação proposta por Zaffaroni, soluções e alternativas para um sistema que há muito encontra-se na fila para ser superado: o cárcere e seus efeitos negativos para o apenado e para a sociedade como um todo. Deste modo, utiliza-se neste trabalho o método analítico-descritivo, por meio da pesquisa bibliográfica, tendo como ponto de partida o problema da pena de prisão e por objeto de estudo e, também, proposta de solução de referido problema, as visões abolicionistas e minimalistas de Hulsman, Mathiesen e Christie, de modo a auxiliar o leitor a refletir acerca dos malefícios do sistema prisional atual e de novas formas de composição de conflitos, pouco ou nada utilizadas nos dias atuais.

\section{A INEFICÁCIA DA PENA DE PRISÃO}

A pena de prisão não cumpre as funções para as quais ela foi idealizada. A privação de liberdade, atualmente, não ressocializa, não transforma seu usuário, que lá está pelo cometimento de algum tipo penal, a conviver em sociedade; pelo contrário, socializa-o a uma cultura carcerária em que os estigmas ${ }^{93}$ advindos da sua estadia no cárcere são graves (GOFFMAN, 1980). As consequências, para o apenado, para sua família e para a sociedade, comprovadamente, são o oposto daquilo para que a privação da liberdade e a instituição carcerária foram criadas. E, tão preocupante quanto, não trava a reincidência e não impede o cometimento de novos crimes. Com isso, a sua população aumenta, gradativamente, todos os dias.

Desde o momento em que a prisão se converteu na principal resposta aos delitos cometidos no seio da sociedade, a partir do século XIX, acreditou-se que ela poderia ser um meio idôneo para realizar todas as finalidades da pena e, posteriormente, reabilitar o delinquente. Tal situação não se concretizou, fazendo com que a pena privativa de liberdade

\footnotetext{
${ }^{93}$ Nesse trabalho, leia-se o conceito da palavra "estigma" a partir de Erving Goffman, em sua obra "Estigma: Notas sobre a Manipulação da Identidade Deteriorada”, de 1980.
} 
mergulhasse numa verdadeira crise, que abrange, inclusive, o seu objetivo ressocializador, tendo em vista a impossibilidade deste em obter qualquer efeito positivo sobre o apenado. (BITENCOURT, 2011).

Apesar de o discurso contemporâneo se dar em face da ressocialização e reabilitação aos usuários do sistema penal, existem fatores materiais, psicológicos e morais no universo carcerário que demonstram a ineficácia quanto ao alcance dessas metas. As determinações previstas na Lei de Execuções Penais, tais como aquelas com relação aos alojamentos e higiene, são ignoradas, o que contribui para deteriorar a saúde dos detentos. As unidades carcerárias em melhores condições são consideradas em estado precário, causando danos físico-psíquicos aos segregados. Além disso, a prisão é um lugar onde se dissimula e se mente, exigindo-se de quem lá se encontra, inclusive, comportamentos inadequados para a sua própria sobrevivência no sistema; tudo, por fim, caminhando no sentido de contribuir para o amadurecimento criminoso do condenado. (BITENCOURT, 2011).

Ainda, há de se falar na questão da prisionalização do apenado, ou seja, todo o processo de sua socialização dentro de uma unidade prisional. No entendimento de Baratta (2011), a prisionalização acontece em duas fases. Em um primeiro momento, ocorre a desculturação, que, conforme o autor, significa

[...] a desadaptação às condições necessárias para a vida em liberdade (diminuição da força de vontade, perda do senso de autorresponsabilidade do ponto de vista econômico e social), a redução do senso da realidade do mundo externo e a formação de uma imagem ilusória deste, o distanciamento progressivo dos valores e dos modelos de comportamento próprios da sociedade externa. (BARATTA, 2011, p. 185).

Há também a segunda parte, que á a aculturação do apenado. Essa situação comporta a

[...] assunção das atitudes, modelos de comportamentos, dos valores característicos da subcultura carcerária. Estes aspectos da subcultura carcerária, cuja interiorização é inversamente proporcional às chances de reinserção na sociedade livre, têm sido examinados sob o aspecto das relações sociais e de poder, das normas, dos valores, das atitudes que presidem estas relações, como também sob o ponto de vista das relações entre os detidos e o staff da instituição penal. (BARATTA, 2011, p. 185).

É como se fosse um processo, nas palavras de Goffman (2011), de mortificação do eu, ou seja, a pessoa é despida de tudo que tinha em sua vida anterior ao cárcere, deixando para trás suas roupas e seus bens, tendo seu cabelo cortado, recebendo uniformes ao invés de roupas e sendo, por fim, remodelada para permanecer naquela instituição - ou seja, a pessoa é institucionalizada, deixando de ter um nome e passando a ser chamada por determinado número. 
Pode-se concluir, portanto, que o atual sistema apresenta um resultado inverso daquele que lhe é cobrado. Com Zaffaroni, quando versa sobre o assunto:

\begin{abstract}
A prisão ou cadeia é uma instituição que se comporta como uma verdadeira máquina deteriorante: gera uma patologia cuja principal característica é a regressão, o que não é difícil de explicar. O preso ou prisioneiro é levado a condições de vida que nada têm a ver com as de um adulto: é privado de tudo que o adulto faz ou deve fazer usualmente em condições e com limitações que o adulto não conhece (fumar, beber, ver televisão, comunicar-se por telefone, receber ou enviar correspondência, manter relações sexuais, etc.). por outro lado, o preso é ferido na sua autoestima de todas as formas imagináveis, pela perda de privacidade, de seu próprio espaço, submissões a revistas degradantes, etc. a isso juntam-se as condições deficientes de quase todas as prisões: superpopulação, alimentação paupérrima, falta de higiene e assistência sanitária, etc., sem contar as discriminações em relação à capacidade de pagar por alojamentos e comodidades. (ZAFFARONI, 1991, p. 136).
\end{abstract}

A pena privativa de liberdade deveria abranger a transformação comportamental do indivíduo, além de buscar no trabalho uma peça de socialização progressiva dos detentos; além do mais, a educação do preso, por parte do poder público, seria uma precaução indispensável no interesse da sociedade e uma obrigação para com o apenado (FOUCAULT, 2013). É, entretanto, uma realidade distante, pois a prática não encontra a teoria no tocante ao encarceramento como forma de efetivo controle e restauro social.

Assim, a pena é apenas um fenômeno político, sem finalidade alguma de caráter racional, tendo sido inventada apenas para legitimar o exercício de um poder político vertical e corporativo; considerando, então, a pena como um fato político, como um fato de poder, poder-se-ia reduzir o âmbito do poder punitivo como um objetivo político de forma muito clara. (CARVALHO, 2013b).

Já sobre os efeitos da pena de prisão relacionados ao usuário de tal sistema, pode-se concluir que

Privar alguém de sua liberdade não é uma coisa à toa. O simples fato de estar enclausurado, de não poder mais ir e vir ao ar livre ou onde bem lhe aprouver, de não poder mais encontrar quem deseja ver - isto já não é um mal bastante significativo? O encarceramento é isso.

Mas é também um castigo corporal. Fala-se que os castigos corporais foram abolidos, mas não é verdade: existe a prisão, que degrada os corpos. A privação de ar, de sol, de luz, de espaço; o confinamento entre quatro paredes; o passeio entre grades; a promiscuidade com companheiros não desejados em condições sanitárias humilhantes; o odor, a cor da prisão, as refeições sempre frias onde predominam as féculas - não é por acaso que as cáries dentárias e os problemas digestivos se sucedem entre os presos! Estas são provações físicas que agridem o corpo, que o deterioram lentamente. (HULSMAN; CELIS, 1993, p. 61-62). 
Em que pese tais males serem parte da realidade do usuário do sistema prisional, constata-se que ele não para de crescer $^{94}$. Neste ponto,

O número de pessoas privadas de liberdade eleva-se a cada ano. Contudo, o aumento da opção pelo encarceramento não é acompanhado pela garantia das condições carcerárias, contribuindo para a violência no interior do sistema, a disseminação de doenças e o crescimento das facções criminais que comandam o mercado de ilegalidades dentro e fora das prisões. (CIFALI; AZEVEDO, 2016, p. 47)

As condições deploráveis do interior do sistema observam, também, uma trágica realidade acerca do espaço utilizado pelos apenados. Nota-se que

Criou-se na cela um mundo paralelo de semi-objetos, mesmo os cartazes glamorosos pararam no tempo, as beldades retratadas não sabem que estão ali, em suas poses tão especiais, os casos novos, agora já velhos, tudo já antigo, promessas sufocadas. Os fios se embrulham, as faíscas estão mortas, os contraditórios ventiladores sem pás só podem existir ali. A umidade vem de todos os lados, contrasta com a secura daquilo que apenas existe e a penetra. $\mathrm{O}$ desarranjo carcomido do espaço, dos espaços, é a ordem vigente das lembranças; cada ranhura - e tudo as possui - testemunha um olvido, um erro ou uma errância, uma refração ou um desvio, um caminho estranho para chegar até o presente passavelmente colorido por uma luz que bem mais esconde do que mostra. (SOUZA, 2016, p. 125-126).

Logo, não é difícil concluir que a prisão é uma instituição condenada à falência - ou, quiçá, já faliu, visto que

Sob vários aspectos, a prisão revelou-se uma experiência falha, que não é capaz de cumprir os objetivos a ela assinados. No que diz respeito à prevenção de novos delitos, o método não é eficaz no convencimento daqueles dispostos a praticar uma conduta ilícita. A conhecida seletividade de nosso sistema penal encarrega-se de levar à prisão os mesmos indivíduos de sempre - negros e pargos, pobres e de baixa escolarização -, motivo pelo qual os que não se encaixam em tal perfil sentem-se seguros o suficiente para seguirem uma empreitada criminosa. Ademais, a grande maioria das pessoas não pensa em termos de custo/benefício no momento de praticar um crime, ainda mais quando falamos em condutas motivadas por ganhos consideráveis vinculados aos mercados ilegais, ou no "calor da emoção". (CIFALI; AZEVEDO, 2016, p. 49).

Fala-se, então, de um sistema superlotado, que desrespeita os direitos humanos e que, inclusive, fora denunciado à Comissão Interamericana dos Direitos Humanos, a partir da situação do Presídio Central de Porto Alegre (CARREIRA, 2018). Restando clara a realidade falha da pena de prisão, deve-se buscar outra resposta, que pode ser compreendida através dos ideais abolicionistas e minimalistas, significando tais teorias, além de uma imperiosa crítica ao sistema prisional, uma nova forma de pensar e agir frente aos males causados pela pena de prisão. O movimento abolicionista

\footnotetext{
${ }^{94}$ Conforme a já referida linha da população prisional, que apresenta um aumento contínuo desde o ano de 1990.
} 
[...] não é só uma utopia que constata exclusões e discriminações; é uma prática de liberdade que não desconhece o poder dos juízes, promotores, advogados, técnicos das humanidades, pais, educadores, administradores e carcereiros. Diante do drama gerado por furtos, roubos, sequestros, homicídios, violentações e acidentes jamais apaziguados pelo direito penal, remete aos riscos da tragédia ao propor a conciliação para interceptar práticas punitivas.

O abolicionismo penal é mais do que abolição do direito penal ou da prisão moderna. Ele problematiza a sociabilidade autoritária que funda e atravessa o Ocidente como pedagogia do castigo em que, sob diversas conformações históricas, atribui-se a um superior o mando sobre outro. (PASSETTI, 2012, p. 16).

O abolicionismo e o minimalismo congregam autores que partilham da crítica sociológica às agências penais e comungam, também, de inúmeras e variadas propostas para a radical substituição do sistema penal por instâncias não punitivas de resolução de conflitos. (CARVALHO, 2013b).

Dessa forma, a partir do próximo tópico, passa-se ao estudo de cada um deles, entendendo sua crítica, em um primeiro momento ao sistema prisional e seus resultados e, após, buscando-se apresentar as propostas que sugeridas pelos dois movimentos, que objetivam substituir um sistema que, por não atingir os seus objetivos, tornou-se inadequado.

2.1 As variantes do abolicionismo penal: Eugenio Raúl Zaffaroni em busca das penas perdidas

Podem ser considerados diferentes tipos de abolicionismo, dando ênfase ao abolicionismo radical do sistema penal, ou seja, a substituição da instituição carcerária por outros meios de solução de conflitos. Tal movimento surge "nas duas últimas décadas, como resultado da crítica sociológica ao sistema penal". (ZAFFARONI, 1991, p. 97).

Segundo Zaffaroni (1991), os autores abolicionistas não partilham de uma total coincidência de métodos, pressupostos filosóficos e táticos para alcançar seus objetivos, uma vez que provêm de diferentes vertentes de pensamento; portanto, o autor propõe quatro tipologias distintas, não conflitantes, representadas por Michel Foucault, Louk Hulsman, Thomas Mathiesen e Nils Christie. É de se ressaltar, ainda, que, em que pese Zaffaroni insira Christie em uma perspectiva abolicionista, referido autor se considera um minimalista, pois acredita não ser possível abolir totalmente o sistema penal, aceitando a pena em certos casos, por ser inevitável a sua utilização (CHRISTIE, 2011).

Logo, passar-se-á a analisar a ideia central de cada um dos referidos autores, de modo a explicitar modos pelos quais eles referem-se aos movimentos abolicionistas e minimalistas, como forma de proporcionar uma nova visão aos problemas enfrentados pelo sistema penal. 


\section{MICHEL FOUCAULT E O ESTRUTURALISMO DO PODER NOS ESTABELECIMENTOS CARCERÁRIOS}

Michel Foucault, muito embora não possa ser considerado um abolicionista como os demais autores, é a primeira referência da teoria em estudo, visto que sua análise estrutural de poder, principalmente a relativa aos estabelecimentos carcerários, conferiu importantes subsídios ao movimento (CARVALHO, 2013b).

Para se entender o objetivo abolicionista, então, antes se faz necessária a compreensão do entendimento de controle social de Foucault (2013), a partir de sua obra Vigiar e Punir, que demonstra o controle dos indivíduos por uma espécie de poder, quando este, através de instituições como hospitais, escolas e prisões, vigia e pune as pessoas, como uma forma de controle da vida social. Pode-se extrair do pensamento do autor que:

[...] não se deve ditar às pessoas como agir, prescrevendo suas ações, mas sim mostrar o real funcionamento das instituições; as verdadeiras consequências de seu funcionamento nos diferentes segmentos sociais; mostrar a história desses sistemas e como eles influenciam no nosso modo de pensar e agir e, por fim, é necessário trabalhar com os envolvidos a fim de modificar as instituições e suas práticas, desenvolvendo, assim, outras formas de pensamento. (BARIZÃO, 2012, p. 4).

Uma das consequências lógicas do discurso de Foucault é a de romper com a ideia do sistema punitivo. O objetivo da reforma, portanto, nasceria com a própria prisão. Conhecemse todos os seus inconvenientes, e sabe-se o quanto ela é perigosa e inútil; entretanto, não se encontra o que pôr em seu lugar. (FOUCAULT, 2013). A reforma não traz a substituição, apenas continua legitimando um sistema que sempre servirá aos mesmos fins de controle.

Tendo em vista essa primeira crítica à forma de controle social na privação de liberdade, a resposta para tal incógnita, ou seja, o que se colocar no lugar da prisão, pode ser observada nos ideais teóricos dos demais autores, que serão estudados na sequência.

\section{O SISTEMA PENAL EM QUESTÃO: O ABOLICIONISMO NA PERSPECTIVA DE LOUK HULSMAN}

Louk Hulsman concluiu que o sistema penal é um problema em si mesmo; logo, diante de sua crescente inutilidade na solução de conflitos, preferível a sua abolição total como 
sistema repressivo (ZAFFARONI, 1991). O autor vê a prisão como sendo não apenas a retirada do condenado do mundo normal da atividade e do afeto, mas também a entrada do indivíduo em um universo artificial onde tudo é negativo, concluindo a privação de liberdade ser um sofrimento desprovido de sentido (HULSMAN; CELIS, 1993).

Ainda, existe o modo como a sociedade enxerga os usuários do sistema carcerário. Mostrar os condenados à prisão como culpados que merecem um castigo alimenta a seu respeito o espírito de vingança.

\begin{abstract}
Algumas pessoas falam da prisão como se fosse um hotel quatro estrelas, apresentando o preso como uma espécie de veranista às custas do Estado. Daí, surgem os protestos dos que levantam a voz, quando se propõe a melhoria das condições penitenciárias: que os presos paguem por seus erros! Não se pode dar comodidade a estes fora-da-lei, enquanto tantas pessoas honestas vivem miseravelmente! (HULSMAN; CELIS, 1993, p. 71).
\end{abstract}

Questionando se a atual Justiça é um mecanismo de exclusão definitiva, já que a vítima do sistema torna-se, também, culpada para o resto da vida, atesta-se que

O sistema penal produz efeitos totalmente contrários ao que pretende um determinado discurso oficial, que fala em "favorecer a emenda do condenado". O sistema penal endurece o condenado, jogando-o contra a "ordem social" na qual pretende reintroduzi-lo, fazendo dele uma outra vítima. (HULSMAN; CELIS, 1993, p. 72). (HULSMAN; CELIS, 1993, p. 72).

Outro detalhe importante é o fato do sistema penal roubar o conflito das pessoas diretamente envolvidas nele (HULSMAN; CELIS, 1993). No instante em que o problema cai no aparelho judicial, já não pertence mais àqueles que o protagonizaram, "etiquetados de uma vez por todas" como delinquente e vítima. Dessa forma,

\begin{abstract}
A vítima não pode mais fazer parar a "ação pública", uma vez que esta "se pôs em movimento"; não lhe é permitido oferecer ou aceitar um procedimento de conciliação que poderia lhe assegurar uma reparação aceitável, ou - o que, muitas vezes, é mais importante - lhe dar a oportunidade de compreender e assimilar o que realmente se passou; ela não participa de nenhuma forma de busca da medida que será tomada a respeito do "autor"; ela não sabe em que condições a família dele estará sobrevivendo; ela não faz nenhuma ideia das consequências reais que a experiência negativa da prisão trará para a vida deste homem; ela ignora as rejeições que ele terá que enfrentar ao sair da prisão. (HULSMAN; CELIS, 1993, p. 82-83).
\end{abstract}

O sistema penal impõe um único tipo de reação aos acontecimentos que entram em sua competência formal: a reação punitiva. Portanto, “a justiça penal é incontrolável, distribuidora de sofrimento desnecessário, materialmente desigual e expropriadora dos direitos dos envolvidos no conflito, principalmente das vítimas". (CARVALHO, 2013b, p. 252).

Para Hulsman, 
[...] há três motivos fundamentais a favor da abolição do sistema penal: é um sistema que causa sofrimentos desnecessários que são distribuídos socialmente de modo injusto; não apresenta efeito positivo sobre as pessoas envolvidas nos conflitos; e é sumamente difícil de ser mantido sob controle. (ZAFFARONI, 1991, p. 98).

Abolir o sistema penal significaria "dar vida às comunidades, às instituições e aos homens"(HULSMAN; CELIS, 1993, p. 92-93). Então,

Existiriam, constata, inúmeras possibilidades de acertamento e de reações possíveis além da punição como, por exemplo, a compensação, a mediação, a conciliação, a arbitragem, a terapia, a educação, etc. a concentração do problema na coerção punitiva traduz falsas soluções, pois unilaterais e arbitrárias. (CARVALHO, 2013b, p. 253).

Importante ressaltar que o autor concentra-se, no que tange ao abolicionismo, em campos que se designam por criminalidades convencionais, ou seja, acontecimentos que afetam as coisas e o patrimônio (furto, estelionato, vandalismo, dentre outros); a segurança das pessoas contra atendados físicos (como, por exemplo, lesões corporais e roubo a mão armada); e a segurança da moradia. (HULSMAN; CELIS, 1993).

Em um primeiro momento, existe a necessidade da mudança de linguagem, ao afirmar que não será possível superar a lógica do sistema penal se não se rejeitar o vocabulário que o sustenta (HULSMAN; CELIS, 1993). Os conflitos, então, passam a ser chamados de “situações problemáticas", que podem, por sua vez, encontrar soluções efetivas entre as partes envolvidas, em um

[...] cara a cara similar a modelos de solução de conflitos (compensatório, terapêutico, educativo, assistencial, etc.) que, diferentes do modelo punitivo, têm a vantagem e não serem, ao contrário deste modelo - cuja aplicação exclui, automaticamente, os restantes - necessariamente alternativos. (ZAFFARONI, 1991, p. 99).

Existe, ainda, a indagação acerca da possibilidade de que a eliminação do sistema penal implique em multiplicação de atos violentos. Tal afirmação pressupõe que, por um lado, o sistema protege contra essa espécie de risco; do outro, que ele é o único mecanismo a garantir tal proteção. Percebe-se, porém, que o sistema penal não impede o cometimento de crimes, e que a espera para que ele acabe com a criminalidade acaba por ser em vão. (HULSMAN; CELIS, 1993).

O que falta, entretanto, não seriam procedimentos não-penais de controle, mas uma vontade política clara e decidida no sentido de aplicá-los (HULSMAN; CELIS, 1993). Dessa forma, o autor traz ao debate a possibilidade de soluções cíveis aos problemas hoje tutelados pela esfera penal. 
4.1 Mecanismos sociais de solução de conflitos e o sistema cível

Hulsman (1993) ensina que a solução de problemas interpessoais em contextos privados acontece com muito mais frequência do que se imagina. Segundo ele, quando surgem os conflitos, o comum é que os envolvidos busquem pessoas próximas a fim de resolver tal problema. Da mesma forma, antes de tomar uma decisão difícil, o autor afirma que as pessoas aconselham-se com familiares ou amigos. Tais mecanismos são instrumentos de regulamentação social, de tal forma que a solução, na maioria dos casos, é tomada mediante o auxílio de terceiros. Neste sentido,

\begin{abstract}
Quando num grupo, numa comunidade natural, surge um conflito mais ou menos agudo, mais ou menos permanente, é comum os interessados, seus parentes, seus amigos procurarem uma maneira de desativar o conflito. Não raro somos chamados a intervir numa discussão entre vizinhos. Espontaneamente, tentamos aplanar certas dificuldades entre casais ou certos problemas de convivência entre pais e filhos. Procuramos desanuviar o ar, quando surge no trabalho uma situação tensa entre colegas ou companheiros. E, muitas vezes, em nossa própria vida, não pensamos em pedir conselho, ajuda, a mediação de alguém, para podermos aceitar um acontecimento doloroso, tomar uma decisão fundamental, iniciar um diálogo difícil? Estes "mecanismos naturais de regulamentação social" são empregados a todo momento e constituem fatores de desalienação. $\mathrm{O}$ fato de não estarmos mais sozinhos diante de um problema torna tal problema mais suportável. Procurar uma solução junto com os outros já constitui, em si, uma atividade libertadora. (HULSMAN; CELIS, 1993, p. 129).
\end{abstract}

Porém, quando formas naturais de solução de conflitos falham, as partes buscam mecanismos artificiais para resolverem seus problemas. Entram em cena os tribunais, que informam o que é de direito de cada um nas situações conflituosas, a fim de que os litigantes recuperem seu lugar, sua honra, seus bens perdidos. Não haveria, portanto, qualquer razão para se acrescentar um poder de punir a tribunais repressores, a fim de que pessoas sejam castigadas. Os tribunais cíveis, com algumas modificações a considerar, poderiam, portanto, intervir de maneira mais útil do que o atual sistema penal (HULSMAN; CELIS, 1993). Considerando tais ideais, "a estratégia não seria, portanto, centrada apenas na gradual abolição da coerção criminal, mas do próprio sistema de justiça penal, substituindo-o pelo mecanismo informal e flexível das justiças civil e administrativa". (CARVALHO, 2013b, p. 254).

Assim, Hulsman apresenta três formas de resolução alternativa de conflitos: o confronto, a arbitragem e as community boards, que serão objetos de estudo no tópico a seguir.

\title{
4.1.1 o confronto, a arbitragem e as community boards
}


Existem experiências que vêm sendo postas em prática como formas alternativas para resolução dos conflitos, sem que haja a necessidade de leva-los à esfera penal, condenando o autor do fato através do sistema punitivo estatal. A primeira ideia é a do confronto, onde o acusado e a vítima ficam cara a cara, buscando chegar a um consenso para a situação problema apresentada.

Trata-se de uma espécie de confronto organizado pela polícia. Antes da questão ser encaminhada aos tribunais, as pessoas que deram a notícia do fato são convidadas a se encontrar com seus adversários e a se questionar se realmente querem que seu problema entre no sistema penal. Nos lugares onde a experiência se desenvolvia, quando tive conhecimento dela, eram estudantes de direito que encaminhavam os confrontos. Normalmente, estes culminavam numa espécie de compromisso. (HULSMAN; CELIS, 1993, p. 133).

Outra forma é a chamada arbitragem, que ocorre por meio de um conciliador treinado a intervir em conflitos. Nesse sentido,

\begin{abstract}
Algumas questões são levadas diretamente a um conciliador, seja porque as pessoas assim o decidem, seja porque são encaminhadas por organismos de assistência social de proteção de menores, ou por organizações, como as formadas pela Igreja, para resolver conflitos internos. Os conciliadores recebem um treinamento que os prepara para intervir em conflitos. O conciliador ouve as pessoas separadamente, prepara uma espécie de compromisso e apresenta sua proposta a cada um dos interessados, eventualmente modificando-a até que seja aceita por todos. (HULSMAN; CELIS, 1993, p. 133-134).
\end{abstract}

Por fim, a terceira proposta de Hulsman são as chamadas community boards, que são formados por um grande número de conciliadores totalmente diferentes daqueles da fórmula da arbitragem, e que ocorre diretamente no seio da sociedade, por meio de cidadãos comuns, com características pessoais parecidas daquelas pessoas envolvidas no conflito.

Estes conciliadores formam comissões ad hoc, compostas de membros escolhidos de acordo com as pessoas que solicitam a intervenção do Community Board. Se o conflito se dá entre portorriquenhos ou entre mexicanos, há pelo menos um portorriquenho ou um mexicano na comissão; se o conflito opõe um homem a uma mulher, terá que haver ali um homem e uma mulher; se o conflito se desenvolveu entre um comerciante e jovens, terão que estar ali um comerciante e jovens.

A ideia básica é a de que os membros da comissão sejam pessoas próximas dos implicados no conflito. Outra ideia igualmente importante caracteriza este modelo de resolução de conflitos: os conciliadores não são preparados para resolver conflitos, mas sim treinados para não propor soluções. Eles são formados para ajudar as pessoas a reconhecerem por si mesmas a natureza do conflito, a escutarem umas às outras, a procurarem compreender a situação vivida pelo outro e, afinal, a decidirem o que fazer com o conflito: retomá-lo e em que contexto, ou encerrá-lo ali. (HULSMAN; CELIS, 1993, p. 134).

É importante ressaltar que Hulsman não impõe a eliminação da coerção, mas do sistema penal em si. Quanto à referida questão, "uma coisa é suprimir a mecânica penal. 
Outra coisa é excluir toda coerção" (HULSMAN; CELIS, 1993, p. 113). Desse modo, mesmo estando o abolicionismo em funcionamento, seria preciso

[...] dar à polícia, no âmbito da manutenção da paz pública, a possibilidade de prender um indivíduo que está atacando outro, ou que se recuse a deixar determinadas situações - como ela faz em outras circunstâncias, numa atuação de emergência. (HULSMAN; CELIS, 1993, p. 113).

Entende-se, por fim, que abolindo o sistema penal, repensado em uma nova linguagem e o retomado em outra lógica, toda a matéria de resolução de conflitos se transformará desde o seu interior. A renovação do sistema não eliminaria as situações problemáticas, mas o fim das chaves de interpretação redutoras e das soluções estereotipadas por ele impostas, de cima e de longe, permitiria que, em todos os níveis de vida social, irrompessem milhares de enfoque e soluções que, hoje, mal se poderia imaginar. Assim, Hulsman justifica seu trabalho, buscando novas alternativas que tragam resultados efetivos e mais humanos, diferentes daqueles ineficazes praticados, em sua maioria, nos dias de hoje.

\section{THOMAS MATHIESEN, O ESTRATEGISTA DO ABOLICIONISMO PENAL}

Zaffaroni (1991) considera Mathiesen o estrategista do abolicionismo, já que vincula a existência do sistema penal à estrutura produtiva capitalista, aspirando, dessa forma, à abolição de todas as estruturas repressivas da sociedade. Segundo ele,

Mathiesen adota posições marxistas de Estado, considerando-o como instrumento de dominação da classe dirigente contra a população pobre e oprimida, acreditando que o Direito Penal funciona como elemento de dominação dessa opressão, defendendo a tese de que o encarceramento atinge massivamente pessoas pobres, consideradas desinteressantes ao sistema capitalista. $^{95}$

$\mathrm{O}$ autor utiliza o exemplo histórico da caça às bruxas na Espanha, citando que o sistema penal pode se desintegrar em poucos anos. Ressalta, porém, que apesar de não ser totalmente possível sua aplicação nos dias atuais, a abolição de certas práticas do sistema penal não se considera impossível de ser realizada (MATHIESEN, 1997). Desta forma, ele relaciona oito itens que fundamentam as suas teses para a extinção da prisão:

\footnotetext{
${ }^{95} \mathrm{O}$ abolicionismo penal tomou contornos definidos como uma força social crítica ao sistema das punições no pós-II Guerra evidenciando as intencionalidades políticas dos mecanismos jurídico-policiais de repressão dos eventos sociais, tipificados pela lei penal como crimes. (RODRIGUES, 2012, p. 146).
} 


\begin{abstract}
Aliado à ideia de reforma permanente e gradual, Mathiesen reivindica o processo de moratória na construção de novas instituições prisionais a partir de oito premissas: $\left(1^{\text {a }}\right)$ a criminologia e a sociologia demonstraram que o objetivo de melhora do detento (prevenção especial) é irreal, sendo constatável efeito contrário de destruição da personalidade e a incitação da reincidência; $\left(2^{a}\right)$ o efeito da prisão no que diz respeito à prevenção geral é absolutamente incerto, sendo possível estabelecer alguma relação do impacto de políticas econômicas e sociais na dissuasão do delito; $\left(3^{\mathrm{a}}\right)$ grande parte da população carcerária é formada por pessoas que praticaram delitos contra a propriedade, ou seja, contra bens jurídicos disponíveis; $\left(4^{\mathrm{a}}\right)$ a construção de novos presídios é irreversível; $\left(5^{\mathrm{a}}\right)$ o sistema carcerário, na qualidade de instituição total, tem caráter expansionista, ou seja, suscita novas construções; $\left(6^{a}\right)$ as prisões funcionam como formas institucionais e sociais desumanas; $\left(7^{\mathrm{a}}\right) \mathrm{o}$ sistema carcerário produz violência e degradação nos valores culturais; $\left(8^{\mathrm{a}}\right)$ o custo econômico do modelo carcerário é inaceitável. (CARVALHO, 2013b, p. 247-248).
\end{abstract}

Como proposta para a solução dos problemas atuais do sistema punitivo, Mathiesen considera duas teses que reduziriam de forma drástica a necessidade da pena de prisão: o direcionamento de políticas sociais aos sujeitos vulneráveis e a descriminalização das drogas (CARVALHO, 2013b).

Se é fato notório que grande parte da população carcerária é composta por pessoas que praticaram crimes contra o patrimônio, ação social nessa área reduziria sobremaneira os problemas derivados da pobreza e do desemprego - "a guerra contra o crime deveria tornar-se uma guerra contra a pobreza. No que tange à descriminalização das drogas, o autor sustenta que esta política atingiria o epicentro do crime organizado, "neutralizando o mercado ilegal e reduzindo drasticamente a quantidade de crimes. (CARVALHO, 2013b, p. 249).

Por fim, outro aspecto importante da obra de Mathiesen são as novas formas de proteção à vítima, que compreenderiam compensação financeira do Estado, sistema de seguro simplificado, apoio econômico em casos de luto, abrigos protetivos e centros de apoio para mulheres espancadas (MATHIESEN, 1997), dentre vários outros meios de solução de conflitos. Ou seja, o autor propõe uma verdadeira escala de apoio ao invés de uma escala de punições, que seria fundamental para superar a atual lógica do sistema punitivo.

Se a abolição da pena de prisão é um sonho impossível? Para Mathiesen, a conclusão é muito apressada. Entretanto, é bom lembrar que nunca houve qualquer transformação social significante na história sem que, antes, não se tenha sido considerada irreal, estúpida ou utópica pela maioria dos especialistas (MATHIESEN, 1997).

\title{
6 NILS CHRISTIE E O MINIMALISMO: UM SISTEMA ENCARREGADO DE PRODUZIR DOR E SOFRIMENTO
}


Nils Christie entende que o sistema penal, em especial no que diz respeito à pena de prisão, somente é encarregado de produzir dor e sofrimento (CARVALHO, 2013b). Zaffaroni entende que o seu abolicionismo penal, em tom minimalista, em muito se compara ao de Louk Hulsman, destacando, expressamente, a "destrutividade das relações comunitárias do sistema penal, seu caráter dissolvente das relações de horizontalidade e os consequentes perigos e danos da verticalização corporativa” (ZAFFARONI, 1991, p. 101).

Com denúncias explícitas ao sistema do tratamento e ao modelo etiológico, Christie aborda temas como instituições, métodos e periculosidade. Desde o paradigma da reação social, fundamenta a desconstrução das políticas da criminologia tradicional em três premissas: $\left(1^{\mathrm{a}}\right)$ os centros de tratamento do delinquente são similares, quando não idênticos, aos cárceres comuns; $\left(2^{\mathrm{a}}\right)$ os métodos científicos são inexitosos, pois nunca impediram a reincidência; e $\left(3^{a}\right)$ conceitos clínicos como periculosidade são absolutamente isentos de predicação. (CARVALHO, 2013b, p. 250).

Para o autor, o maior inimigo do ser humano é o Estado; no entendimento do Christie, ao cair numa prisão, seja em qualquer lugar do mundo, são grandes as chances de sair morto, ou destruído, do ponto de vista psicológico e social, de lá. (LANDIN NETO, 2008).

Como forma de solução aos atuais problemas punitivos, a justiça participativa e comunitária seria uma alternativa viável. Ela buscaria um processo de composição de conflitos, abdicando da privação ou da restrição de liberdade como penas, ganhando espaço, como resposta, a reparação ou a indenização pelo dano causado. É errada, portanto, a suposição de que o conflito deva ser resolvido, já que não seria necessariamente algo ruim e estariam, ainda, em abundância na sociedade moderna. A vítima, considera Christie, é uma espécie de perdedora em dobro (CHRISTIE, 2017), primeiro face ao ofensor e, logo após, ao Estado, já que é excluída de qualquer participação no próprio conflito. Esta perda se transforma em uma perda de oportunidades de esclarecimentos, de possibilidades pedagógicas, de ensejo de uma discussão contínua sobre o que representa a lei do país.

[...] nos últimos anos temos assistido a um maior interesse em medidas nãocriminais, como uma alternativa à punição, a maioria das quais é baseada em discussões diretas entre as partes, que muitas vezes terminam acordos para reparar o dano. Esta mudança vai desde o uso do monopólio da pena pelo Estado às tentativas para permitir que as partes tenham a oportunidade de conhecer e encontrar maneiras de reparar o dano. Estas ideias em conjunto são chamados de "ideais abolicionistas", embora algumas vezes são encontradas sob nomes como "descarcerização ou descriminalização" 96 (SCHEERER, 1989, p. 139).

\footnotetext{
${ }^{96}$ No original: “[...] en los últimos años hemos observado un mayor interés por la aplicación de medidas no penales, como una alternativa al castigo, la mayoria de las cuales se basa en discusiones directas entre las partes, que con frecuencia terminam en acuerdos de reparación del daño causado. Este cambio va desde el uso monopólico de la pena por parte del estado hacia los intentos por permitir que las partes tengan oportunidad de encontrarse y buscar por sí mismos formas de reparar el daño. Estas ideas em conjunto se llaman "ideas
} 
A compensação das vítimas também seria uma óbvia solução (CHRISTIE, 2017). O autor alega, inclusive, que o ressarcimento é uma espécie de seleção natural a que recorrem quase todos os povos do mundo (LANDIN NETO, 2008). Ele afirma que a "estatização do conflito revitimiza o sujeito passivo ao impedir sua participação na resolução do caso" (CARVALHO, 2013b, p. 251). Dessa forma, a compensação da vítima é uma solução comumente óbvia que já é utilizada pela grande parte das pessoas no mundo na maioria das situações (CHRISTIE, 2017). Assim, a busca da paz e o ressarcimento da vítima são pilares nas teses adotadas por Christie.

Em sua obra Uma Razoável Quantidade de Crime, Christie apresenta dois tipos de justiça: a horizontal e a vertical. Para a justiça vertical, casos iguais devem ser tratados igualmente, conforme regras já estabelecidas. Entretanto, os casos nunca são iguais, cada qual possui aspectos próprios. Logo, a lei formal que vem de cima não pode levar tudo em consideração, necessitando eliminar vários aspectos daquela situação (ou seja, o que é irrelevante). Para definir o que é irrelevante, devem-se criar regras específicas; logo, existem limitações sobre o que pode ou não ser discutido. Com a justiça vertical, cria-se uma distância social que implica, também, punição e inflição consciente de dor. Há um contraste frontal com a justiça horizontal, quando a relevância é decidida pelas partes do processo; nela, as decisões são tomadas no esteio local; como os problemas são resolvidos em cada região não importa, sendo mais importante que, dentro de cada comunidade, a decisão deve ser considerada a mais justa. Além do mais, as decisões são tratadas de maneira radicalmente diferente do que o corre no sistema legal, uma vez que a relevância consiste em matérias de interesse geral, porém, sem possuírem soluções predefinidas (é relevante tudo aquilo que os participantes consideram relevante). Nesse sentido, a compensação é mais importante que a retribuição, sendo as sociedades mantenedoras de tal justiça, em sua maioria, igualitárias. Punições são particularmente disfuncionais em sistemas como esse, e a inflição de dor (punir) significa gerar uma guerra civil em sistemas frágeis. A compensação, no lugar da dor, se torna uma resposta natural (CHRISTIE, 2011).

A pena não pode se equiparar ao dano, pois a retribuição não conversa com os ideais de humanidade. Salientando que o crime não existe como fenômeno natural, classificando-o apenas uma forma (entre inúmeras) de se enumerar atos deploráveis, aceita a ideia do minimalismo, onde a pena, em certos casos, é inevitável. Aponta o autor que referida posição

abolicionistas", aunque algunas vezes se la encuentra bajo denominaciones como "descarcelación o descriminalización”. CHRISTIE, Nils. Las imagenes del Hombre en el Derecho Penal Moderno. 
proporciona alternativas, pois faz com que a análise parta dos conflitos, e não do crime, viabilizando perspectivas libertadoras (CHRISTIE, 2011).

Não ofertando respostas definitivas para as situações que enfrenta em sua obra, Christie (2011) afirma que são necessários sistemas que olhem adiante, auxiliem o futuro, sistemas para a verdade e para a reconciliação como soluções para a maioria dos casos. Importante ressaltar que ele não advoga pela completa abolição do sistema penal, entendendo que, em alguns casos, não há o que fazer senão afastar o ofensor do meio social em que está. A partir de Christie, então, na dúvida, não se pune; quando se pune, deve ser da maneira menos dolorosa possível (ACHUTTI, 2016).

\section{O MALHETE QUE CONDENA E A MÃO QUE OFERECE UMA CHANCE PARA RECOMEÇAR}

Identificando o abolicionismo - e as suas estratégias ou outras teorias de tom minimalista - como perspectiva e caminho a ser trilhado, propõe-se realizar a tarefa de desvelar as contradições do sistema penal, encarando desafios e descobrindo possibilidades, com o intuito de construir sociedades alternativas, em um nível de transições constantes, nunca terminadas, com pequenos objetivos visando outros maiores (ÁVILA; GUILHERME, 2015).

Entender a estratégia abolicionista como inacabada é fundamental para transcendermos ao dualismo entre revolução e reforma. É possível desejarmos uma sem abrirmos mão da outra. É possível pensarmos em superar as masmorras medievais, desde que saibamos que o horizonte a seguir é o da liberdade. (ÁVILA; GUILHERME, 2015, p. 105).

Mais que uma nova forma de olhar o mecanismo punitivo moderno, portanto, "o abolicionismo penal é um percurso no qual pessoas atuam lado a lado compondo um fluxo que vai dos envolvidos na situação-problema aos intelectuais nas universidades, construindose uma nova linguagem" (PASSETTI, 2012, p. 27). No entendimento de Carvalho (2013b), abandonar teorias que justificam a pena, inclusive os modelos ressocializadores, é primordial para iniciar-se a perspectiva de redução de danos penais.

Uma política prisional, alternativa, haverá de romper com o paradigma tradicional, marco da prevenção especial positiva. Não se haverá de excogitar de políticas penalógicas, substitutivas do cárcere, de feição, nitidamente, reformista e humanitária. Uma autêntica política carcerária deverá ter o cariz de profundas reformas sócio-institucionais - o que poderá ser alcançado, somente, no marco do 
desenvolvimento da igualdade democrática. É urgente a transformação radical e a superação das relações sociais de produção, gestadas pelo modelo capitalista. Caso contrário, a prisão continuará existindo, como um teatro de tragédias, silenciosas, apesar de anunciadas, cujos atores serão sempre recrutados, preferencial e seletivamente, nas camadas desfavorecidas da sociedade.

O pecado original da prisão é a própria prisão. O cárcere destrói qualquer pedagogia de tratamento. (TRINDADE, 2003, p. 60).

Abolir castigos significa valorar novos costumes, criar sociedades sem pena, libertárias, em que as partes buscam solucionar seus próprios problemas dispensando a forma punitiva do direito penal (PASSETTI, 2012)

Ao contrário daqueles que professam as verdades do movimento lei-ordem, os abolicionistas não acreditam no Direito Penal como resposta sadia ao fenômeno violência: ele não cumpre e não pode cumprir as promessas que justificam a sua existência: não inibe o crime e não recupera o delinquente - uma grande mentira, uma ilusão, um mito, portanto, porque há profundo descompasso entre as ditas intenções e aquilo que resulta na vida, portanto. (CARVALHO, 2013a, p. 45).

Por fim, abdicar da pena da maneira pela qual hoje ela é imposta, com todos os estigmas causados ao usuário e à sua família, além da sociedade que o recebe após o período atrás das grades, é encorajar novas formas de composição social de conflitos, amparando a vítima tanto quanto o autor do fato. De um lado, a reparação a quem sofreu com o erro de outrem; de outro, ao invés do malhete a condenar, uma mão estendida a oferecer uma segunda chance, uma oportunidade de reparar o mal cometido, uma aproximação da sociedade a um dos princípios pilares do direito: o princípio da dignidade humana.

\section{CONSIDERAÇÕES FINAIS}

A pena de prisão, instituição que objetiva cumprir as funções de retribuição, prevenção e ressocialização, não cumpre com o que dela é esperado. Ao contrário, ao adentrar no sistema, o usuário passa a ser socializado para outro mundo, um mundo que possui costumes e regras que não são aceitas no lado de fora das grades. Isso estimula o aumento em conjunto das linhas do aprisionamento, do cometimento de novos crimes e da reincidência.

Em vista disso, diversos são os autores e movimentos que propõem por meio de uma feroz crítica ao sistema penal e sua principal instituição, a prisão, ideias e conceitos novos que visem a sua total - ou quase total - supressão. A partir de Zaffaroni, encontram-se várias ideias de cunho abolicionista que partilham de uma nova visão de sociedade, mais justa e centrada no princípio da dignidade humana. Em meio a percursos abolicionistas e ideais 
minimalistas, a concepção de buscar algo melhor que o direito penal é comum e é o caminho que leva à conclusão - e à crítica - no sentido de que algo deve ser feito.

Michel Foucault, em que pese não possa ser considerado um abolicionista, contribuiu para o movimento em suas diversas obras, apontando pontos importantes sobre as estruturas de poder e tecendo considerações sobre o entendimento do controle social e controle dos indivíduos por meio de instituições como escolas e prisões, transformando-os em corpos dóceis. Criticou ferozmente a forma da privação de liberdade, por meio de uma construção histórica, e encaminhou o problema que, posteriormente, seria enfrentado por outros autores; no caso do presente estudo, deu-se ênfase aos abolicionistas e minimalistas Hulsman, Mathiesen e Christie.

Louk Hulsman pode ser considerado um verdadeiro abolicionista, posto que não assume a possibilidade de qualquer instituição que derive do sistema penal em suas propostas teóricas. Busca o autor, em um primeiro momento, a superação da linguagem desde uma perspectiva acadêmica, pois só assim será possível chegar ao próximo passo, que é a abolição completa do sistema penal. Ao contrário da repressão penal, apresenta formas diversas de soluções de conflitos, tais como a arbitragem, o confronto e as community boards - todas, diga-se de passagem, devolvendo a solução da situação-problema nas mãos dos envolvidos e da comunidade para que, dessa forma, possam buscar no seio local o meio mais adequado, pacífico e não-prisional de solucionar o ato motivo de discussão.

Considerando um mínimo de pena em seu abolicionismo - ou um abolicionismo minimalista -, encontra-se Thomas Mathiesen, que considera o Estado um instrumento de dominação da classe dirigente contra a oprimida. Chegando a se questionar se a abolição seria um sonho impossível ou uma utopia, responde negativamente a tal pergunta, utilizando exemplos históricos, como a caça às bruxas ou a abolição da escravatura. Ponto importante de sua obra, o apoio à vítima é de extrema importância, e se perfaz em compensações financeiras, apoio por parte do Estado e abrigos protetivos. Uma verdadeira escala de apoio ao invés de uma escala de punições.

Outro autor importante estudado foi Nils Christie, autointitulado como um minimalista em sua obra Uma Razoável Quantidade de Crime. Condena toda a inflição de dor desnecessária causada ao ser humano que adentra no sistema prisional; assim, propõe soluções diversas, tais como processos de composição de conflitos, a reparação e a indenização pelo dano causado pelo autor do crime. Insere a vítima de volta ao processo conflitivo, já que, segundo o autor, este lhe é tomado quando o Estado assume o direito de punir, ocasionando uma espécie de perda em dobro para ela - além de, ainda, caracterizar-se 
aí uma perda de oportunidades. Após sua crítica à questão da prisão, não oferta respostas definitivas, mas afirma ser necessária a construção de sistemas que olhem adiante, que busquem a reconciliação na maioria dos casos. Christie, por fim, é enfático: na dúvida, não se pune, e quando a punição acontece, deve ser realizada da maneira menos dolorosa possível.

Portanto, existem vieses que caminham desde o minimalismo, que aceita um mínimo de pena, seja como um fim em si mesma ou um meio ao abolicionismo total, até o abolicionismo radical, que suprime de uma só vez todo o sistema penal, posto que a sua simples reforma não seria capaz de resolver o problema que advém da cultura do encarceramento dos dias atuais.

Certo é que, em relação à cultura do encarceramento que impera nos dias atuais, algo precisa ser feito. A prisão não funciona como deveria. Em meio a todas as questões levantadas, a importância em se enfrentar o problema se dá na mesma perspectiva da teoria abolicionista: um percurso que nunca deve deixar de ser trilhado, transformando-se em um caminho contínuo que culmine em pequenas soluções que, passo a passo, atinjam o grande objetivo de se encontrar uma definitiva resposta sobre a questão da inflição de dor que, há tempos e ainda hoje, é o cárcere.

\section{REFERÊNCIAS}

ACHUTTI, Daniel. Justiça restaurativa e abolicionismo penal: contribuições para um novo modelo de administração de conflitos no Brasil. São Paulo: Saraiva, 2016.

ÁVILA, Gustavo Noronha; GUILHERME, Vera M. Abolicionismos penais. Rio de Janeiro: Lumen Juris, 2015.

BARATTA, A. Criminologia crítica e crítica do direito penal: Introdução à sociologia do direito penal. 6 ed. Rio de Janeiro: Revan, 2011.

BARIZÃO, Elaine Fernandes. Abolicionismo penal: uma abordagem teórica. Revista Eletrônica de Ciências Sociais, Uberlândia, 2012. Disponível em: <http://www.sociais.ufu.br/recs/edicoes/v2n2/7.pdf $>$. Acesso em 11 de setembro de 2016.

BITENCOURT, C. R. Falência da pena de prisão: causas e alternativas. 4. Ed. São Paulo: Saraiva, 2011. 
CARREIRA, Matheus. Brasil é denunciado na OEA por situação precária de presídio no RS. O Globo. Disponível em: https://oglobo.globo.com/brasil/brasil-denunciado-na-oea-porsituacao-precaria-de-presidio-no-rs-7253673. Acesso em: 22 de fevereiro de 2018.

CARVALHO, Amilton Bueno de. Direito Penal à marteladas: Algo sobre Nietzsche e o Direito. Rio de Janeiro: Lumen Jurirs, 2013a.

CARVALHO, Salo de. Antimanual de criminologia. 5. edição. São Paulo: Saraiva, 2013b.

CHRISTIE, Nils. Las imagenes del Hombre en el Derecho Penal Moderno. In: SCHEERER, Sebastian et al. Abolicionismo. Buenos Aires: Ediar, 1989.

CHRISTIE, Nils. Uma razoável quantidade de crime. Rio de Janeiro: Revan, 2011.

CHRISTIE, Nils. Limites à dor: o papel da punição na política criminal. Belo Horizonte: D’Plácido, 2017.

CIFALI, Ana Cláudia; AZEVEDO, Rodrigo Ghiringhelli de. Medo, descaso e violência no Brasil: como romper esse ciclo? In: MARQUES, J. et al. Cárcere em imagem e texto. Porto Alegre: Livraria do Advogado, 2016.

FOUCAULT, Michel. Vigiar e punir: história da violência nas prisões. Petrópolis, Rio de Janeiro: Vozes, 2013.

GOFFMAN, Erving. Estigma: notas sobre a manipulação da identidade deteriorada. Rio de Janeiro: Zahar, 1980.

HULSMAN, Louk; CELIS, Jacqueline Bernat de. Penas perdidas: o sistema penal em questão. Niterói: Luam, 1993.

LANDIN NETO, José Cícero. O abolicionismo e a ressocialização do condenado. Âmbito Jurídico, Rio Grande, 2008. Disponível em: <http://www.ambitojuridico.com.br/site/index.php?n_link=revista_artigos_leitura\&artigo_id=5035>. Acesso em 30 de julho de 2016.

MATHIESEN, Thomas. A caminho do Século XXI - Abolição, um sonho impossível? In: PASSETTI, Edson; SILVA, Roberto Baptista Dias da. Conversações abolicionistas: uma crítica do sistema penal e da sociedade punitiva. São Paulo: IBCCrim, 1997. 
PASSETTI, Edson. A atualidade do abolicionismo penal. In: PASSETTI, Edson et al. Curso livre de abolicionismo penal. 2.ed. Rio de Janeiro: Revan, 2012.

RIBEIRO, Juliana do Val; VIRGENS, Eufrásia Maria Souza das. A absurda prisão de mão com bebê recém-nascido. Estadão. Disponível em:

http://politica.estadao.com.br/blogs/fausto-macedo/a-absurda-prisao-de-mae-com-beberecem-nascido/. Acesso em: 22 de fevereiro de 2018.

RODRIGUES, Thiago. Drogas, proibição e abolição das penas. In: PASSETTI, Edson et al. Curso livre de abolicionismo penal. 2.ed. Rio de Janeiro: Revan, 2012.

SOUZA, Ricardo Timm de. Por ao menos um instante, o umbigo do universo. In:

MARQUES, Jader et al. Cárcere em imagem e texto. Porto Alegre: Livraria do Advogado, 2016.

TRINDADE, Lourival Almeida. A ressocialização: uma disfunção da pena de prisão. Porto Alegre: Sérgio Fabris, 2003.

ZAFFARONI, Eugenio Raúl. Em busca das penas perdidas. Rio de Janeiro: Revan, 1991.

\title{
DIALOGGING BETWEEN ABOLITIONIST COURSE AND MINIMALIST IDEALS: PARAMETERS FOR THE SEARCH FOR ALTERNATIVE SOLUTIONS TO THE CONSEQUENCES OF JAIL CULTURE
}

\begin{abstract}
The starting point of this article was, at a first moment, to understand how the prison sentence is presented today. Understanding its consequences and the processes to which it subjects its clientele, and realizing, therefore, that the main institution of the penal system does not attend to the anxieties to which it is called to answer, one went then to the analysis of alternative solutions to imprisonment - main object of study of this work. Starting from Eugenio Raul Zaffaroni's work In Search of Lost Feathers, the work brought proposals for a solution to the problem faced by prisoners and their consequences through abolitionist and minimalist writers, in common, suggestions and projects for the abolition of the penal system in force, in whole or in part, especially with regard to the substitution of the sentence of imprisonment by other mechanisms for the solution of conflicts and /
\end{abstract}


or reparation of damages. For this, in the present study, the analyticaldescriptive method was used, through bibliographic research.

Keywords: Abolitionism. Minimalism. Prison. Alternative solutions. 